\title{
The Drivers of Structural Changes
}

\author{
Jianfang Liu \\ Guanghua School of Management, Peking University, Beijing 100871, China \\ Email:755232093@qq.com
}

\begin{abstract}
Structural change is an important feature in the process of economic growth. Most economies in the process of economic growth have appeared similar structural adjustment. The primary industry labor share declines; the tertiary industry labor share increases; the secondary industry labor share presents an inverted u-shaped change. This paper aims to analyze the driving mechanism of structural transformation from the perspectives of supply, demand, input and output, international trade and government public expenditure, and finally make a prospect for future structural transformation research from the perspectives of producer heterogeneity and consumer heterogeneity as well as the fourth wave of technological change - artificial intelligence.

Keywords: structural change, supply, demand, input-output, international trade, government policy
\end{abstract}

\section{Introduction}

Following seminal contributions in the first half of the 20th century, structural transformation or structural change usually defined as the reallocation of economic activity across the broad sectors of agriculture, manufacturing and services - has been the object of rising interest in the literature over the last few decades.

What are the main driving forces behind structural change? This paper aims to analyze the driving mechanism of structural transformation from the perspectives of supply, demand, input and output, international trade and government public expenditure.

In addition, artificial intelligence is becoming a new round of technology and industrial change trend, which is quietly changing the world. This is another major advance of human civilization after the industrial age, the electric age and the information age. Artificial intelligence contributes to the transformation and upgrading of industrial structure. Artificial intelligence is leading to profound changes in the industrial structure. More and more traditional industries are taking artificial intelligence as the new driving force for transformation and upgrading in the transformation of new driving forces.

\section{The drivers of structural changes}

Most of the literature mainly studies the driving mechanism of structural transformation from two aspects of supply and demand. In recent years, scholars have begun to analyze structural transformation from the perspectives of input-output and open economy. In addition, the government works as the main force of regulating economy, and the government's productive expenditure can also drive structural transformation. This paper combs the literature on the driving mechanism of structural transformation from these aspects.

\subsection{Demand-driven and structural transformation}

These aspects include demand analysis of the industrial structure change, the main emphasis on Engel's law, the influence of industrial structure, the growth of the economy, the level of per capita income, and people's demand structure change. From agricultural products to manufactured goods, from the necessities to luxury goods, they reflect the change of demand structure and the corresponding adjustment of industrial structure. The literature analyzes the industrial structure change, from the perspectives of demand drive, income effect; it analyzes the consumption structure changes, the income elasticity of demand and consumption externality influence on industrial structure. The income effect refers to the improvement of income level; people's consumption demand will change with the change of the income elasticity and income elasticity; the more consumer goods, the higher it promoted the change level of demand structure. Different income elasticity reflect different consumer preferences, and industrial structure change from the demand side. These researches present the utility function.

Literature on the analysis of industrial structure from the perspective of non-homothetic preference structure can be roughly divided into two categories. One is the use of Stone-Geary preference to analyze the effects of Engel's law on the process of economic growth, such as Kongsamut et al. (2001) ${ }^{[9]}$. They think with differences between consumers' preferences for different product, under the action of the income effect, with the improvement of consumer income level, 
demand elasticity in larger products production department is growing faster than that in smaller products production , leading to production factors flow from low growth sector to high growth sector. The other is the non-homogeneous order utility function generated based on sequential consumption preference. These literatures believe that with technical progress and innovation, more and more new products and emerging industries will be created. That is to say, the product has a life cycle, and new invention product level is higher, which belongs to the luxury goods. With the technology progress, the status of the product is replaced by newly invented products, becoming a staple of the lower level. A consumer preference for new products is greater than the old products. In order to promote the rapid development of new products industry, the constant adjustment of industrial structure is made. With the passing of time and the increase of product variety, the impact on the economy of unit product is more and more small. Structural changes are also gradually flattening out.

Kongsamut (2001) explains the kaldor and kuznets facts by establishing a three-sector model comprising agriculture, manufacturing and services. In the utility function, the minimum consumption of agricultural products needed for survival and work and the amount of household production services in service consumption are introduced to reflect the non-potential similarity of the utility function, whose utility function is expressed as follows: $U=\int_{t=0}^{\infty} e^{-\rho t} \frac{\left[\left(c_{a t}-\bar{a}\right)^{\alpha}\left(c_{m t}\right)^{\beta}\left(c_{s t}+\bar{s}\right)^{1-\alpha-\beta}\right]^{1-\sigma}-1}{1-\sigma} d t$. It can be seen from this preference setting that the income elasticity of consumption of agricultural products is less than 1; the income elasticity of consumption of manufactured goods is equal to 1 ; the income elasticity of consumption of services is greater than 1 . Under the assumption of exogenous technological progress, the total output and total income increase, and with the increase of income, the higher proportion of consumption expenditure in the service sector increases, while the lower proportion of agricultural consumption increases, resulting in the shift of industrial structure. It is also proved that the model can explain both kaldor facts and kuznets facts under the condition of blade condition. Under this preference setting, when the time approaches infinity, the employment ratio of various industries tends to be stable, but in fact, the degree of non-likelihood of this preference declines rapidly, and the economic structure tends to flatten quickly.

In addition, the Stone-Geary preference is set so that when the minimum endowment consumption of a sector is zero, its employment ratio remains constant, which is consistent with reality ${ }^{[9]}$. Li Shangao and Gong Liutang (2012) on the basis of the model, the preferences of a sex in the biochemical, assuming that the lowest agricultural products consumption is affected by agricultural income and agricultural inputs, while the household production services because of the influence of income and employment in service industry service industry, changes in the consumption share of lag and output, the change of share and share changes faster than output share changes ${ }^{[12]}$.

When the number of consumer goods in a household is more than three, the setting of the dislocation-like preference theory and stone-geary utility function is not applicable. Therefore, it is necessary to adopt the hierarchical preference theory to study the economic growth and structural changes under a variety of consumer goods. Foellmi and Zweimuller (2008) think that as technology advances, new product research and development will promote the expansion of new industry lead to the decline of the old industry, the income elasticity of demand is different, different products and structure change driven by nonlinear Engel-curve is derived from the people income increase caused by the change of the consumption structure. They constructed a model containing three sectors of agriculture, industry and service industry. Under the hypothesis of sequence preference, original new products for high income elasticity of luxury are more. With the passing of time, the requisite of income elasticity is low. The consumption cycle generated by the nonlinear Engel-curve is the fundamental cause of the structural change.

Moreover, the nonlinear Engel-curve is consistent with the kaldor fact only when the intertemporal substitution elasticity satisfying the consumption is constant ${ }^{[7]}$. Comin, Lashkari and Mestieri (2016) constructed a CES utility function, introduced the parameter of different income elasticity of consumption in various industries, and found that the proportion of department elements with high income elasticity in the industry increased continuously until the economy convergences to one department ${ }^{[4]}$. Alonso Carrera and Raurich (2015) set up the minimum consumption demand ratio of GDP to the lowest levels of consumer demand, found that as long as the minimum initial levels of consumer demand is small enough, the balance of the total structure change and economic growth can occur at the same time, the original rich countries benefit from the lower minimum consumption demand and the ratio of GDP, and can realize the structure change and balanced growth at the same time, but the original poor countries with higher minimum consumption demand and the ratio of GDP, overall economic variables can only be for a long time not balanced growth, And these countries will probably never achieve aggregate balanced growth or structural change ${ }^{[3]}$.

Hori, Ikefuji and Mino, (2015) will be used to form the utility function, introduced in the form of a ratio, constructs a not a preference structure of three sector model to analyze the external habit formation effect on industrial structure, they 
think the structure change is odd order preference to jointly with the departments growth difference, assume that habit formation is derived from the external habit, different departments of the consumption of the strength of the external habit formation effect, found that the greater the strength of habit formation effect on welfare, the department and the higher the growth rate of output, and labor and capital and other factors of production into the department, in the three departments include agriculture, manufacturing and services model. Assuming that the impact intensity of externalities is from low to high in agriculture, manufacturing and service industry, it is found that the output share and consumption share of the agricultural sector decline, while the output share and consumption share of the service sector increase, while the output share and consumption share of the manufacturing sector first increase and then decline, presenting a u-shape. This paper is different from the previous literature research perspective and method, from a new perspective, when consumers consider the impact of personal consumption on the consumption of various sectors, this consumption externality on the economic structure $^{[8]}$.

\subsection{Supply-driven and structural changes}

From the perspective of supply-driven, it is mainly caused by the difference in technological progress between departments and the degree of capital deepening. Supply-driven is the price effect. The growth rate of output between departments, the degree of technological progress and the degree of capital deepening affect the relative price of output of departments, thus leading to the flow of production factors in departments. This kind of literature can be roughly summarized as follows. Baumol first analyzed the influence of inter-sector output growth rate difference on economic growth and structural change from the perspective of supply side. He believed that inter-sector factor flow mainly came from the relative price difference caused by inter-sector output growth rate difference.

Ngai and Pissarides (2007), constructs a total factor productivity in different departments model, to analyze the technology progress rate of structural change and economic growth, the influence of their key assumption is total factor productivity is different between government departments and exogenous, given output price difference comes from the rate of technological progress, the structural change due to total factor productivity differences between departments, think in economy, balanced growth factors of production eventually transfer to production of capital and the lowest total factor productivity departments ${ }^{[13]}$.

Acemoglu and Guerrieri (2008) on Ngai and Pissarides, on the basis of the analysis from the perspective of capital deepening structural change and economic growth, they constructed a two department non-equilibrium growth model, the critical assumptions division between the technological progress is exogenous, the output elasticity of capital is different, under this assumption, the industrial structure change from departments between elements of different intensity and capital deepening, capital deepening added a capital-intensive sector output growth, at the same time also can make production factors flow from the unit. With the continuous structural changes among sectors, the proportion of inter-sectoral factors and the deepening of capital lead to unbalanced growth among sectors. Finally, the economy converges to one sector and the total volume is balanced growth under a single sector ${ }^{[1]}$.

Tibiao Chen (2007), on the basis of constructing a contain intermediate and final product departments multi-sectoral model, at the same time accommodate Carl many facts and Kuznets-fact, assuming that intermediate products division production, according to ke sermons glass forms and exogenous technological progress rate given is different, the rate of technological progress led to the relative price differences, and different growth rate of output intermediate products, intermediate products division between the elements of the flow direction depends on the elasticity of substitution between intermediate product and technical progress rate differences. ${ }^{[16]}$

Furthermore, Alvarez-cuadrado, Long and Poschke (2016) believed that the difference in the elasticity of substitution of production factors between departments was a factor leading to the structural change, constructed the CES production function form of the constant elasticity of substitution of departments, assumed that the elasticity of substitution between production factors of departments was different, and analyzed the changes in labor income share of different departments ${ }^{[2]}$.

\subsection{Structural changes under open economy}

There are relatively few literatures on the establishment of theoretical models to analyze structural changes under the open economy, mainly including Matsuyama (2008), Yi and Zhang (2013) and Mao and Yao (2010) $)^{[10][17][14]}$.

Matsuyama (2008) argue that productivity theory explains the productivity gains of the manufacturing result in many countries the share of manufacturing output decline tendency, presents the camel growth, a conclusion can be achieved in the closed economy, but in the model assumes that the economy is closed, but want to use data to predict under open economy is wrong, closed economy model cannot be used to explain the global perspective changes in manufacturing employment share, depend on each other's countries into open economy model. He built a simple model of the world 
economy to analysis the tendency of manufacturing productivity growth to lead to a decline in the share of employment. But across countries, the faster total factor productivity in manufacturing rose, the faster the share of manufacturing output fell. Matsuyama economic growth from the income elasticity and departments two angles to analyze the change of the manufacturing employment share. He thinks that if manufacturing grows quickly, income level will be high. But manufacturing income elasticity of demand is small compared to the service industry. As the growth of the manufacturing industry, it does not appear to match the growth in consumption, making the manufacturing share drop. But under the open economy, manufacturing productivity is high, and has a comparative advantage. Foreign demand will increase employment. Under the action of two kinds of factors, fast manufacturing growth situation with no employment share has fallen dramatically.

From the perspective of the productivity, the manufacturing and services are subject to less elasticity of substitution, and manufacturing grows too fast. It cannot make consumers with manufactured goods replace the service. Manufacturing products price is lower, so the employment share declines, but that doesn't mean the faster manufacturing growth also declines in the employment share. If manufacturing productivity increases too fast, both the price effect on the supply side and the relative income effect on the demand side will cause the share of manufacturing to decline, while the effect of open economy is just the opposite. Just because of this, the rapid growth of manufacturing does not cause a sharp decline in the share of employment around the world. ${ }^{[10]}$

Yi and Zhang (2013) established a sector productivity growth of different contains two countries three departments of simple analysis framework, a factor of production if product can trade, agricultural and manufacturing department in services trade, factors of production labor flow only in the domestic, and not only multinational transfer, at the same time there are barriers to trade, international trade cost nonzero, none of the Stone - Geary preferences, analysis of productivity differences among the departments, trade cost and the income and the elasticity of substitution effect on the structure change. In a closed economy, each sector's share of employment is the same as its share of consumer spending, whereas in an open economy, each sector's share of employment is the sum of its share of spending and the ratio of net exports to total GDP for the tradable sector. Therefore, the optimal conditions under the equilibrium state of closed economy and the optimal conditions under the open economy are different.

The employment share of each country's sector with a comparative advantage is higher than that under the closed economy, and the net export surplus of each sector exists. In the open economy, sectors without comparative advantages will face a very low price. When the elasticity of substitution between sectors is relatively small, the expenditure share of these sectors without comparative advantages will decrease, and the corresponding employment share will also decline. For non-tradable services, the price level of services in an open economy is higher than that in a closed economy, and more factors will flow into the sector. The dynamic model of Yi and Zhang (2013) lies in the changes of productivity and trade costs of its sectors over time. These changes alter the patterns of relative prices and specialization, so that both expenditure and the path of specialization determine the dynamic nature. In particular, in sectors where the share of spending has fallen but the share of net exports has risen, the share of employment may not have fallen under either of these two factors, in line with the hump in the share of manufacturing employment and output in the world in recent decades ${ }^{[17]}$.

Mao and Yao (2010) attempted to analyze the results of hump structural changes in open economies with general characteristics. Similarly, it is assumed that agriculture and manufacturing are tradable sectors and services are nontradable sectors, that agriculture USES labor and land for production, that manufacturing and services use capital and labor for production, and that capital and labor can flow freely between sectors. At the same time, it is assumed that the total factor productivity is different between sectors, and the elasticity of substitution between the service sector and the two other categories of products is less than 1 . The output share of the agricultural sector declines, while that of the service sector increases. And that of the manufacturing sector shows a hump.

On the one hand, although manufacturing sector productivity grows quickly, its product prices have not fallen. To attract labor from the agricultural sector and agricultural sector in the model at the same time, another except labor inputs of land supply is limited, and the department of agriculture technological progress does not change in the law of diminishing marginal productivity of the element. On the other hand, when the tradable sector output grows too fast, prices rise. Due to the elasticity of less than 1 in services and manufacturing, services prices rise and can't be replaced by consumer products manufacturing. This allowed Labor to flow into the service sector. In the initial stage, the rapid growth of manufacturing production attracted most of the labor into the sector. In the later stage, the price of manufactured products fell, but it could not replace the service industry, which led to the outflow of labor force, resulting in hump growth. Land, a factor of production, ensured that the share of agriculture declined over time, and the stability of relative prices between the manufacturing and agricultural sectors ensured that the share of manufacturing employment rose in the 
initial stage, and finally the labor force flowed into the service sector under the Balassa-Samuelson effect ${ }^{[14]}$.

\subsection{Input-output and structural changes}

While the recent multi-sector growth literature has primarily investigated the final demand channels, particularly the income and relative price effects, through which the structural change process can take place in market economies, a number of studies stress the importance of taking explicitly into consideration the input-output or sectoral linkages. Firms offering final goods and services are in turn 'consumers' of intermediates.

Under the influence of global trade imbalance, trade in services, trade barriers and other factors, Sposi, M. (2019) investigates the influence of input-output linkage on structural changes by using a more general analytical framework. It is revealed that input-output correlations (sectoral linkages) in different countries have the following characteristics: in the agricultural sector, intermediate inputs in rich countries are more intensive than those in poor countries, while the share of agricultural output in rich countries is lower than that in poor countries; in all sectors, rich countries invest more heavily in services than poor ones, especially in the service sector $^{[15]}$.

\subsection{Government public expenditure and structural changes}

Fiscal expenditure is the necessary input of economic operation, which is a key variable affecting national economy. Fiscal spending including government consumption expenditure and government investment, metastatic three parts, government consumption and metastatic spending have important influence on the consumer, such as education, health care, social security expenditure has a promoting effect on consumption, international studies have shown that government spending in these areas not only can partly replace residents consumption in this respect, indirect increase people's income, can also reduce residents fear of the future is uncertain, which further increases the other consumption. Government investment boosts economic growth by making companies more productive. A large number of literatures have proved that public capital formed by fiscal investment is the key force driving economic growth. Fiscal expenditure provides enterprises with production efficiency and technical efficiency through public capital formed by investment. Fiscal expenditure can also boost total demand by increasing resident income, thus promoting economic growth.

The channels for fiscal expenditure to promote the change of industrial structure mainly include: fiscal expenditure on science, education, culture and health improves the productivity of agricultural sector and increases the output of unit labor, thus promoting the outflow of labor force from agricultural sector. Financial expenditure on education improves the level of human capital, enabling labor to find jobs in more competitive sectors, increasing the range of work options, and facilitating the outflow of labor from the agricultural sector and other sectors; Through the above functions and direct transfer payments, fiscal expenditure increased residents' income. With the increase of total income, residents' consumption demand shifted from daily necessities to non-daily necessities at a higher level. Fiscal expenditure directly promotes the production efficiency of enterprises through the formation of public capital, thus promoting the economic growth of various sectors. However, the difference in financial investment in different industries and the difference in the production efficiency of public capital lead to the difference in the output growth of different sectors, driving the change of industrial structure from the perspective of supply.

Lifeng Zhang (2015) interpretation from the perspective of government public expenditure economic structure change, he built a contains more government productive expenditure of public service and public capital sector growth model, the total output by multiple intermediate product output aggregation, assuming different sector output elasticity of public spending, the elasticity of substitution between intermediate product department is less than, the department in charge of the public expenditure elasticity, employment share decline. In this model, balanced growth can be achieved, and the share of productive services expenditure and income tax have similar effects on the overall economic growth rate. As the two increase, the total economic growth rises first and then declines ${ }^{[11]}$.

ChengLiang Yan (2016), by building a productive expenditure and industrial structure model of welfare financial expenditure, the fiscal expenditure on the mechanism and effect of industrial structure change, the study found that the fiscal expenditure is an important driving force of the industrial structure change, the agricultural sector and nonagricultural sector productive fiscal spending and welfare spending by raising the production efficiency and expand two department non-farm products demand to promote labor force from agriculture to non-agricultural sector also, and through the prefecture level panel data analysis. Productive financial expenditure and welfare financial expenditure make the share of labor income of agricultural sector decline ${ }^{[5]}$. Chengliang Yan (2017) by building a contains the agricultural sector and non-agricultural sector and government sector model, using the counterfactual analysis investigates the change of industrial structure and economic growth in China, the study shows that the agricultural sector rising total factor productivity is the basic dynamic change of industrial structure in our country, non-agricultural rise in total factor productivity, capital 
deepening and expansion of fiscal expenditure small contribution to the change of industrial structure in our country, this is likely to be endogenous preference driven demand side factors such as the distortion of the labor market ${ }^{[6]}$.

\section{Summary and outlook}

There are a large number of literatures explaining the driving mechanism of structural changes from the supply and demand levels, but few literatures on input-output, international trade and government policies. Moreover, most of the literature mainly contributes to the theoretical part, and there are few literatures on numerical simulation and empirical analysis, so we need to further quantitatively analyze the role of various driving mechanisms in the structural transformation process based on the theoretical model.

This paper holds that the research on the transmission mechanism of future structural changes can start from the following aspects. (1) Introducing heterogeneous consumers and heterogeneous producers. Under closed economic conditions, families with different income conditions have different consumption demands and consumption structures. Low-income families tend to consume low-end products, such as agricultural products, while high-income families tend to consume high-end products, such as luxury goods. Therefore, the change of household consumption structure will affect the consumption demand and consumption structure of the whole economy. Under the conditions of open economy, richer countries started to produce high-end products earlier, while poorer countries still produced low-end products in large quantities. Such differences in producers led to a large amount of international trade, which further affected the internal production structure of each country. (2) On the one hand, as the fourth industrial revolution, the development of artificial intelligence innovation creates new obtain employment. On the other hand, the interaction between artificial intelligence and other industries greatly improves the labor productivity and has a different degree of substitution effect on different labor. The artificial intelligence services trigger a new way of consumption and increase the marginal utility unit consumption. These aspects of supply and demand cause a new round of transformation and upgrading of industrial structure.

\section{References}

[1] Acemoglu D., Guerrieri V. Capital deepening and non-balanced economic growth. Journal of Political Economy. 2008; 116(3): 467-498.

[2] Alvarez-Cuadrado F, Long Ngo Van, Poschke M. Capital-labor substitution, structural change and growth. Theoretical Economics. 2017; 12(3): 1229-1266.

[3] Alonso-Carrera J., Caballé J., Raurich X. (2011) Sectoral composition and macroeconomic dynamics. Barcelona GSE Working Paper Series. No. 545, Barcelona Graduate School of Economics.

[4] Comin D, Lashkari D, Mestieri M. (2015) Structural change with long-run income and price effects. NBER Working Paper. No. w21595, Available at SSRN: https://ssrn.com/abstract=2666363.

[5] Yan Chengliang. Changes in industrial structure, economic growth and regional development gap. Party and government field of vision. 2016; (10): 59.

[6] Yan Chengliang, Wu Yingjun, Yang Longjian. Financial expenditure and changes in industrial structure. Economic Science. 2016; (1): 5-16.

[7] Foellmi R., Zweimüller J. Structural change, Engel's consumption cycles and Kaldor's facts of economicgrowth. Journal of Monetary Economics. 2008; 55(7): 1317-1328.

[8] Hori T., Ikefuji M., Mino K. Conformism and Structural Change. International Economic Review. 2015; 56(3): 939961.

[9] Kongsamut P., Rebelo S., Xie D. Beyond balanced growth. Review of Economic Studies. 2001; 68(237): 869-882.

[10] Matsuyama K. Structural change in an interdependent world: a global view of manufacturing decline. Journal of the European Economic Association. 2009; 7(2-3): 478-486.

[11] Zhang Lifeng. A multi-sector model of public expenditure and growth. Journal of Economics. 2015; 115(1): 73-93.

[12] Li Shangao, Gong Liutang. Nonhomothetic preference, endogenous preference structure, and structural change. Economic Research Journal. 2012; (7): 35-47.

[13]Ngai L.R., Pissarides C.A. Structural change in a multi-sector model of growth. American Economic Review. 2007; 97(1): 429-445.

[14] Mao Rui, Yao Yang. Structural change in an open economy. Pacific Economic Review. 2012; 17(1): 29-56.

[15]Sposi M. Evolving comparative advantage, sectoral linkages, and structural change. Journal of Monetary Economics. 2019; 103: 75-87.

[16] Chen Tibiao. Sectoral difference in growth rate of technology and change in economic growth rate with hump-shape. 
Economic Research Journal. 2008; (11): 102-111.

[17] Uy T., Yi K-M., Zhang J. Structural change in an open economy. Journal of Monetary Economics. 2013; 60(6): 667682. 